\title{
How Does Tax Share Configuration Promote Industrial Structure Upgrade? \\ Zui-Yi SHEN
}

Institute of economic and management, zhejiang ocean university

Zhoushan,Zhejiang,316000,China

shenzuiyi@zjou.edu.cn

Keywords: Tax structure, Industrial structure upgrade, C-D production function.

\begin{abstract}
The paper shows that in China's tax structure of industry, the increase of tax revenue of secondary industry to total tax share can significantly increase the output elasticity of capital elements; the increase of tax revenue of tertiary industry also increase the output elasticity of capital elements but the influence is more remarkable than secondary industry; and the increase of tax revenue of tertiary industry will increase output elasticity of labor element, but influence is no significant. These exemplified results indicated that in today's Chinese economy, tax structure of industry has hindered the development of the industrial structure, it is necessary to reform taxes in tertiary industry from two aspects of the structure and function to promote industrial structure. It need improve the amount of resources tax and house duty in tertiary industry and reduce the share of business tax to upgrade the industrial structure and promote economic growth.
\end{abstract}

\section{Introduction}

Adjustment and upgrading of industrial structure is an important task of the country and governments at all levels in recent years; the rationalization of the industrial structure is an important means and channels to carry out sustainable economic development; and the reasonable industry tax share configuration can promote the adjustment of industrial structure. Aghion et al.[1]confirmed that the fiscal and taxation policy can alleviate the financing constraints of enterprises and promote the improvement of its productivity. Guoqingwang et al.[2]analyzed the relationship between the tax revenue growth and industrial structure and pointed out that the added value of secondary and tertiary industry improve significantly tax revenue growth in the current tax system structure. Zhangbin[3]made an empirical analysis about the influence of Chinese tax policy on the industrial structure using VAR model. Liujun [4]discussed the influence of the adjustment of the main tax policy including value-added tax and tax exemption on industrial structure optimization. This paper attempts to explain the industrial structure adjustment from the influence of tax structure and point out the adjustment direction of tax structure to promote industrial structure upgrade.

The remainder of this paper is structured as follows: Section 2 introduces characteristics of Chinese industry and its tax structure. The source of data and model are described in section 3. Section 4 make an empirical analysis of the influence of industry tax revenue on industrial structure upgrade.Section 5 concludes the paper.

\section{Characteristics of Tax Structure of Industry}

Tax revenue produces with the production of country,it is the important form for the government to realize its function. In the modern market economy condition, tax possesses basic functions of organizing financial income, adjusting economy and industrial structure[5]. As an important part of the economic system, China's tax system has experienced three development stages since the establishment of PRC. The tax reform of 1994 year is one of the largest and most extensive and profound influence. The reform has constructed the tax system framework of Chinese socialist market economy, and formed a certain characteristics of economic adjustment function. China exist a total of 18 categories of taxes at present through the tax reform in 1994. They are the value added tax, 
consumption tax, business tax, enterprise income tax, individual income tax, resource tax, urban and township land use tax, land appreciation tax, real estate tax, city maintenance and construction tax, car tax, stamp tax, deed tax, farmland occupation tax, vehicle acquisition tax, tobacco taxes, customs tax, vessel tonnage tax.Among them, the value-added tax is the collection for value-added realization of goods in the process of production, sales or services to avoid the double taxation dilemma; consumption tax is the collection of specific consumer goods or consumption behavior, to make the nation regulate production and consumption; business tax is the collection of business and management behavior such as taxable services providing, the transfer of intangible asset and profits of real estate sale; customs duty is the collection of goods which import or export our country frontier or customs. Individual income tax the collection for personal wages, salaries, interest Dividend income; enterprise income tax is the collection of enterprise income;deed tax is the collection of the taker of transferring land and house property right.; farml and occupation tax is the collection of farmland expropriation, to protect resources of cultivated land.

China's tax mainly comes from secondary industry and tertiary industry, especially to some of the main categories of taxes, such as value-added tax, business tax, enterprise income tax, etc. the faster growth of added value in secondary industry and tertiary industry, the faster growth of tax revenue. The growth of industry tax revenue is positively correlated with the upgrading of the industrial structure. Bulletined by department of statistics, the ratio of added value of three industries is 1:4.5:7.2in 2015, the ratio of industry tax collection is 0.1:52.48:67.42[6]. Based on the statistic data of China tax yearbook in 2015, vehicle acquisition tax accounted for almost half of the total revenue of primary industry; to tax revenue of secondary industry, it is value added tax which occupied nearly half of the total revenue. The four categories of taxes of the top tax revenue in tertiary industry were the enterprise income tax, business tax, value added tax, personal income tax and the enterprise income tax and business tax accounted for nearly half industry total tax.

\section{Model and Data Source}

Explanation of the Model. From the point of view of the economy as a whole, namely from the macroeconomic point of view, economic growth produce social output by all sorts of factors of production through the social specialization and division of labor system, or economic system organized together. In a certain production resources conditions, for example, in a certain amount of capital and labor factor conditions, economic growth is mainly decided by the output efficiency of the production elements. The higher the output efficiency of capital and labor is, the greater the total economic output is; the lower output efficiency of capital and labor is, the smaller total amount of economic output is. In the established social specialization and division of labor system and some amount of production factors, the performance of the output efficiency of production elements measures the level of total macroscopic economics. Obviously, to fixed quantity of production elements, the output efficiency of the production elements will be different in different professional and labor division of social system. And a country's tax system, specific speaking from the number is tax structure share of three times industry, will impact on the extent of social labor division and specialization, so as to affect the efficiency of production factors. In addition, from a macroeconomic perspective, an economy may be regarded as a production unit. According to the above shows that production in our country function influenced by the tax structure of three times industry can be expressed as the Cobb - Douglas production function form[7] as follows:

$$
Y=K^{\sum_{i=1}^{3} \alpha_{i} x_{i}} L^{\sum_{i=1}^{3} \beta_{i} x_{i}} e^{\sum_{i=1}^{3} \gamma_{i} x_{i}+\varepsilon}
$$

Where $Y$ is total output; $K$ is usage quantity of capital; $L$ is the input of labor; $x_{i}, i=1,2,3$ is tax share of the total tax revenue in $i$ industry. Both ends of the equation (1) take the log at the same time, and econometric model denoting influence of tax structure of production factors on output efficiency was constructed 


$$
\log (Y)=\sum_{i=1}^{3} \alpha_{i} x_{i} \log (K)+\sum_{i=1}^{3} \beta_{i} x_{i} \log (L)+\sum_{i=1}^{3} \gamma_{i} x_{i}+\varepsilon
$$

It can know from the econometric model (2), parameters $\alpha_{i}$ and $\beta_{i}, i=1,2,3$ respectively denoting the influence of tax revenue share of each industry on output elasticity of capital and labor factors, and at the same time, to a certain extent also denoting the influence of tax structure share on output efficiency of capital and labor; $\gamma_{i}$ denote the influence of the change of tax share of industry structure $\mathrm{x}_{\mathrm{i}}$ on economic production scale in the situation of invariable capital and labor factors, eliminating the impact on output elasticity of capital and labor. If this kind of influence is positive, it means economic production scale expanded in conditions of invariant quantity of capital and labor factor eliminating contributions of capital and labor. This, to a certain extent, shows that the portfolio form of elements of capital and labor is combination form to improve the specialization and labor division of society. On the contrary, if the changes of tax structure share $x_{i}$ produces the negative influence on economic production scale. It means that the portfolio of elements of capital and labor which decided the production scale is the combining form to reduce the degree of specialization and division of labor in society. Therefore, these parameters of $\alpha_{i}$ and $\beta_{i}$ in a certain extent also measure the influence of output efficiency of elements of capital and labor on revenue share of industry tax and of social division of labor the degree of specialization in market economic condition. Following we will make an econometric analysis to the influence of revenue share of industry tax on adjustment of industry structure and economic growth.

Source of Data.Based on $<$ China statistics yearbook $>$, we selected the data of gross domestic product(GDP)from 2005 to 2014 as the output of model (2). Capital investment $\mathrm{K}$ is the data of Gross capital formation and composition, the data of employment personnel of each region distributed by industry as the input of labor $\mathrm{L}$. The tax data of the three industries each region comes from the table of "statistical data of income organized by countrywide tax department and divided by area and industry " in<China tax yearbook>, we can get the sample observations of GDP, capital investment K, labor input $\mathrm{L}$ and industry tax revenue of 31 provinces in our country excluding Hong Kong, Macao and Taiwan municipalities from 2005 to 2014. And compute the proportion of tax revenue $\mathrm{x}_{1}, \mathrm{x}_{2}, \mathrm{x}_{3}$. Now we will econometric analysis of China's tax structure on upgrading of the industrial structure and the influence value is an average composted by different characteristic influence of China's different regions, In analysis and study of the average effect, we mainly use regional sample observation value to study the relationship between the tax structure and economic growth and industrial structure adjustment, the influence of different industry tax revenue in various regional on economic growth and industrial structure adjustment reflected final average influences, so that parameter eventually estimated really reflected the average influence of China's industry tax configuration on the economic growth and the upgrading of the industrial structure. And to study with regional sample observation, not only consider the influence of industry tax configuration changing with time under a kind of economic form condition on economic growth and industrial structure adjustment, also can consider the influence of industry tax configuration of other economic forms changing with time in the same totality on the economic growth and adjustment of industrial structure. For these reasons, we adopt the data of regional sample observation to study the average influence produced by China's tax structure change on industrial structure adjustment.

\section{Empirical Analysis of the Influence of Industry Tax on Industrial Structure}

To regress model (2) using R software, get the estimated parameters as follows in Table1: 
Table1: Parameters estimation of equations

\begin{tabular}{|c|c|c|c|}
\hline \multicolumn{4}{|c|}{ explained variable: $\log (\mathrm{GDP})($ sample $n=310)$} \\
\hline explanatory variable & Equation(3) & Equation(4) & Equation(5) \\
\hline $\mathrm{x}_{1}$ & $\begin{array}{l}775.92 * \\
(2.000)\end{array}$ & $\begin{array}{c}657.4 \\
(1.669)\end{array}$ & \\
\hline $\mathrm{X}_{2}$ & $\begin{array}{l}-775.03^{*} \\
(-1.996)\end{array}$ & $\begin{array}{l}-656.05 \\
(-1.693)\end{array}$ & \\
\hline $\mathrm{X}_{3}$ & $\begin{array}{c}-780.59 * \\
(-2.01)\end{array}$ & $\begin{array}{l}-662.17^{*} \\
(-1.709)\end{array}$ & $\begin{array}{c}-1.92748 * \\
(-2.667)\end{array}$ \\
\hline $\mathrm{x}_{1} \log (\mathrm{k})$ & $\begin{array}{l}-200.87 * \\
(-1.869)\end{array}$ & $\begin{array}{l}-74.44 \\
(-1.666)\end{array}$ & \\
\hline $\mathrm{x}_{2} \log (\mathrm{k})$ & $\begin{array}{l}0.53^{*} \\
(1.87)\end{array}$ & $\begin{array}{c}0.8586^{* * *} \\
(5.246)\end{array}$ & $\begin{array}{c}1.01772 * * * \\
(64.322)\end{array}$ \\
\hline $\mathrm{x}_{3} \log (\mathrm{k})$ & $\begin{array}{l}2.24^{* * *} \\
(4.324)\end{array}$ & $\begin{array}{c}1.6655 * * * \\
(8.941)\end{array}$ & $\begin{array}{c}1.33448 * * * \\
(15.246)\end{array}$ \\
\hline $\mathrm{x}_{1} \log (\mathrm{L})$ & $\begin{array}{l}127.72 \\
(1.285)\end{array}$ & & \\
\hline $\mathrm{x}_{2} \log (\mathrm{L})$ & $\begin{array}{c}0.46 \\
(1.547)\end{array}$ & & \\
\hline $\mathrm{X}_{3} \log (\mathrm{L})$ & $\begin{array}{c}-0.7 \\
(-1.27)\end{array}$ & & \\
\hline R square & 0.9783 & 0.9736 & 0.9996 \\
\hline adjusted R square & 0.97704 & 0.9683 & 0.9996 \\
\hline
\end{tabular}

Note: $*, * *, * * *$, respectively denote that the value significant at the level of $10 \%, 5 \%, 1 \%$. The number in the bracket is the corresponding estimated value of the T statistics.

From qualitative point of view, equation (3) in Table1 shows: the increase of $x_{1}$, the share of tax revenue of primary industry to total tax revenue, will reduce the output elasticity of capital elements in economy, but will improve the output elasticity of labor elements, this kind of influence on improving the output elasticity of labor elements is not very significant and reduce the output elasticity of capital elements in economy is very significant in statistical sense. the increase of the share $\mathrm{x}_{2}$, tax revenue of secondary industry to total tax revenue, and the share $\mathrm{x}_{3}$, tax revenue of third industry to total tax revenue, will reduce overall economic scale. But they can improve output of capital element, and the part of improvement is much larger than the part of the decrease of the overall economy scale; to output elasticity of labor elements, the increase of the share $x_{2}$, the tax revenue of secondary industry to total tax revenue, can increase the output elasticity of labor elements, and the increase of the share $x_{3}$, the tax revenue of tertiary industry to total tax revenue, can reduce the output elasticity of labor elements, These results may be related to secondary industry is a labor intensive industry, tertiary industry is the capital intensive industry, but this kind of influence is not statistically significant.

Eliminating explanation variable of equation (3),which parameter estimation of the corresponding t statistic absolute value no more than 1.547, namely the influence of the share of tax revenue, respectively of primary, secondary, and tertiary industry to total tax revenue, to the output elasticity of labor elements is not significant in statistical sense, again to regress the equation (4). The result of regression showed that, the influence of the share $\mathrm{x}_{2}$, tax revenue of secondary industry to total tax revenue, on the overall economic scale and the share $\mathrm{x} 1$, tax revenue of primary industry to total tax revenue, on the output elasticity of capital elements in economy not fully achieve t test standard (the absolute value of $t$ statistics no more than 1.709), the others $t$ statistics of parameter estimator are all pass the $\mathrm{t}$ test.

Eliminating explanation variable of equation (4), which parameter estimation of the corresponding $t$ statistic absolute value did not through the $t$ test, again to regress equation (5).There was no intercept 
in equation (5), all absolute value of $\mathrm{t}$ statistics of parameter estimation greater than 2 and adjusted $\mathrm{R}$ square in equation (5) equals 0.9996, which far greater than the adjustment $\mathrm{R}$ square(0.9683) in equation (4). All explanatory variables in equation (5) passed the t test. equation (5) not only improve explanation credibility of the single variable to explained variable, but also greatly strengthened explanation degree of the explanatory variable to explained variable on the whole, so using equation (5) to explain the influence of industry tax structure of China's economy on total economic output is more appropriate.

The equation (5) showed that, in China's current economic system and industry tax structure, the share $\mathrm{x} 1$ of tax revenue of primary industry to total tax revenue almost do not produce influence on China's economic development and industrial structure adjustment; every $1 \%$ increase of share $\mathrm{x}_{2}$, tax revenue of secondary industry to total tax revenue, will make the output elasticity of capital increased by $1.02 \%$ in economy, but the output elasticity of labor elements won't produce significant influence on overall economic scale. Every $1 \%$ increase of share $\mathrm{x}_{3}$, the tax revenue of tertiary industry to total tax revenue, will make the output elasticity of capital significantly increased $1.34 \%$ in economy, but won't produce significant influence on the output elasticity of labor elements, and will reduce overall economic scale to the original scale of $\exp (-1.93 \%)$, equals 0.9809 , the reduced scale is not very big. And the tax revenue of tertiary industry enhances the efficiency of capital output higher than the tax revenue of secondary industry.

From the above analysis, we can conclude that in the current industry tax structure, the increase of tax share respectively in primary and secondary industry is not significant to the enlargement of overall scale of economy, but the increase of tax share of tertiary industry will decline the overall scale of the economy, it means there may be some shortcomings in the existing tax structure of tertiary industry. National tax mainly comes from secondary and tertiary industry, and the ratio of tax share of tertiary industry to national tax increases year by year. In tertiary industry, categories of taxes, the tax revenue share of which ordered from big to small, were enterprise income tax, business tax, value added tax, personal income tax, vehicle acquisition tax, land value increment tax, stamp duty, urban maintenance and construction tax, property tax, urban and township land use tax , consumption tax, car tax.

In a certain technical conditions, the size of the overall economy mainly depends on economic and social specialization and the breadth and depth of division of labor, and specialization and the breadth and depth of division of labor depends on the size of the market. In order to expand the market, and to enhance the breadth and depth of social specialization and division of labor, we should reduce the tax share of the enterprise income tax and business tax in tertiary industry,which occupied half of tax share of tertiary industry, and increase the share of other categories of taxes, such as resource tax and the transfer tax.

The increase of the breadth of resource tax share means that the increase of the use of resources, this will surely increase social specialization and division of labor, and increase overall economic scale; in the condition of constant of tax rate, the increase of the transfer tax means that market volume will be increased through some special way of market transaction, thus increase the breadth and depth of social specialization and division of labor, and promote the expansion of the overall size of economy. If capital factor and labor factor is entirely through the market for income, then the decision of income share of capital and labor factor is its output efficiency.

From the above analysis, it is known that in the present tax system structure, the increase of the tax share of tertiary industry to total tax share will increase the output elasticity of capital,and more stronger than secondary industry to capital. Therefore, from the standpoint of function of tax categories, it is necessary to implement a tax reform of value-added tax and enterprise income tax according to the current China's economic system reform and the present situation of the economic structure adjustment, and at the same time, collecting the housing property tax, resource tax, thus the market will get more capital elements to promote the development of tertiary industry, so that in the new situation to better perform the function of promoting industrial structure adjustment.

We can know from the above empirical analysis that in the current tax structure, from the point of view of adjustment of the industrial structure to offer a proposal that tax structure which can most 
effectively promote economic growth and increase the output of capital and labor factor at the same time is to improve the tax share of value added tax in secondary industry and the tax share of resource tax and house duty in tertiary industry, at the same time to reduce the share of the business tax revenue in tertiary industry. If the reform started from the business tax and house duty in tertiary industry and focus on the reform of the economic function of share adjustment of tax and industry tax structure, then the China's economy will will realize the Pareto optimality.

\section{Conclusion}

In this paper, two conclusions have been drawn through using the Cobb - Douglas production function model under the influence of industry tax revenue in our country: the first conclusion is that in China's current stage of the economic system and industrial tax revenue structure, the increase of tax revenue share in primary, secondary industry is not significant to the enlargement of scale of the overall economy, but the increases of tax revenue share in tertiary industry will modest decline the size of the overall economy. The conclusion shows that tax structure of the industry in our country has certain defects at present and must readjust the tax income share of various categories in industry according to the characteristics of taxes itself of various categories to promote the enlargement of scale of the overall economy. The second conclusion is the increase of tax share of secondary industry and tertiary industry to total tax revenue will improve the capital output elasticity of the economy, and the effect of tax revenue share of tertiary industry to the increase of output elasticity of capital was stronger than the effect of secondary industry to capital output.

These conclusions show that we not only need to readjust the tax structure of secondary industry and tertiary industry, but also play economic function after the adjustment of income share to promote the increase of tax revenue share in secondary and tertiary industry, and make the tax revenue share of tertiary industry more than the tax revenue share of secondary industry.

\section{Acknowledgment}

This research was financially supported by the Scientific Research Start-up Foundation for Dr.

\section{References}

[1] Aghion P, Hemous D, Kharroubi E, Cyclical fiscal policy, credit constraints, and industry growth, J. Journal of monetary economics. 62(2014)41-58.

[2] GuoQing Wang, LvBing Yang, Economic growth and industrial structure adjustment to the influence of the tax growth , J. Foreign-related taxation,9(2004)11-16.

[3] ZhangBin, Effect of empirical analysis of tax policy effect on three industry structure adjustment, J.The western accounting , 5(2010), 12-22.

[4] Liujun, actively adapt the tax policy to guide promote industrial structure adjustment,J. Tax research, 282(2008)63-64.

[5] Kuznets,National Income and Industrial Structure, J. Econometrica,17(1949)205-241.

[6] Information on http://www.stats.gov.cn/.

[7] LiShaoRong gengying, China's tax structure, economic growth and income distribution, J. Economic research,5(2005):11-23. 